\title{
Public versus private investment and growth in a hierarchical education system*
}

\author{
Calin Arcalean and Ioana Schiopu \\ Indiana University Bloomington \\ August 2006, this version January 2008
}

\begin{abstract}
The paper studies the interaction between public and private spending in a two-stage education framework (K-12 and tertiary education) and their effects on economic growth. We find that an increase in the overall educational public spending crowds out the total level of private contributions and increases the share of resources that households devote to K-12 education. For a given public budget, a higher share of K-12 public funding prompts households to spend more on education overall and at the same time, to allocate a higher share of their investments towards higher education. We show that the growth maximizing share of public spending devoted to K-12 should be high, irrespective of the size of the public budget and that increased enrollment in tertiary education does not always translate into higher growth. Moreover, to maximize growth, high tax countries should use more of their public resources in tertiary education relative to low tax countries. Our model is broadly consistent with data on education finance in OECD countries. It also suggests that US efforts to improve K-12 education and the reform of higher education in Europe are consistent with the objective of increased economic growth.
\end{abstract}

JEL classification: I22, I28, H23, H52

Keywords: educational public policies, hierarchical education, parental transfers

*Corresponding author: Ioana Schiopu, Department of Economics, Indiana University, WY 105, 100 S. Woodlawn Ave., Bloomington, IN 47405. Email: ischiopu@indiana.edu. We are indebted to Michael Kaganovich and Gerhard Glomm for discussions and suggestions that improved this paper. We thank Richard Romano, Brian Peterson and the participants at the Spring 2007 Workshop in Public Economics at Indiana University, the 2007 Midwest Macro Meeting, the $21^{\text {st }}$ ESPE Congress, 2007 APET Conference for their comments. All errors are our own. 


\section{Introduction}

A highly educated labor force is instrumental for advances in productivity and hence for economic growth 1 . This makes public provision of education a central policy area for governments in all countries, especially in developed nations, where advanced technologies and high living standards are dependent on maintaining high levels of productivity.

However, allocating public resources for education in the developed countries involves more trade-offs now than in the past. On the one hand, mounting social security and health expenditures have put public budgets under pressure and implicitly the resources devoted to education. On the other hand, technological progress has emphasized the distinction between general skills (acquired during primary and secondary education) and specialized skills (produced during tertiary education), so that not only the size, but also the composition of the public spending for education becomes a critical policy issue. This trade-off is further complicated by the hierarchical nature of education. Individuals accumulate basic or general skills during a first stage of education. The attained quality of those skills is crucial for the returns of more advanced education, which builds advanced specialized skills. This brings the natural question on how the education policies should be designed, not only in terms of the budget size, but also the allocation of public resources across different educational stages in oder to achieve the goal of increased human capital.

At the same time, recent policy debates on the education finance have emphasized the increased role of private contributions in the light of the high private returns obtained at all education stages (see Psacharopoulos and Patrinos (2004) for a calculation of these returns). In the OECD countries, significant co-financing takes place at the tertiary and pre-primary educational levels, where respectively $24 \%$ and $19 \%$ of total funds come from private sources (see OECD (2006)). The participation in tertiary education increased worldwide in the last two decades, in response to an increase in both individual and social returns. As a result, the share of private resources in the funding of tertiary education has become more important in both developed and developing countries ${ }^{2}$. However, while decreased public spending leads to the crowding-in of private resources, there is a concern that less public funds might discourage potential students. Thus, insuring the right balance between the two funding sources is also a key aspect of the educational policies.

\footnotetext{
${ }^{1}$ Hanushek and Kimko (2000), Barro (2001), Aghion et al. (2005) Jamison et al. (2006), provide extensive empirical support to this claim.

${ }^{2}$ In one-half of the OECD and partner countries, the private share of educational spending increased by more than 3\% during 1995-2003. In Australia, Italy and the United Kingdom, as well as the partner country Chile this increase exceeded 9\% (see OECD (2006)). According to Li (2005), in China the government contributions have declined drastically, from $83 \%$ in 1990 to $50 \%$ in 2002.
} 
Table 1: Size and structure of education expenditure in the European Union and the United States (\% GDP, 2003). Source: OECD, Eurostat, authors' calculations

\begin{tabular}{|c|c|c|c|c|c|c|c|c|}
\hline & \multicolumn{3}{|c|}{ Private } & \multicolumn{3}{|c|}{ Public } & \multirow[t]{2}{*}{ Total } & \multirow{2}{*}{$\begin{array}{c}\text { Growth } \\
\text { rate }^{1}\end{array}$} \\
\hline & K-12 & Tertiary & Total & $\mathrm{K}-12$ & Tertiary & Total & & \\
\hline $\mathrm{EU19}^{2}$ & 0.39 & 0.33 & 0.72 & 4.01 & 1.26 & 5.27 & 6.04 & 2.55 \\
\hline$\%$ & 54 & 46 & 100 & 76 & 24 & 100 & & \\
\hline US & 0.43 & 1.61 & 2.04 & 4.13 & 1.47 & 5.60 & 7.64 & 3.20 \\
\hline$\%$ & 21 & 79 & 100 & 74 & 26 & 100 & & \\
\hline $\begin{array}{l}1-\mathrm{Av} \\
2-\mathrm{De}\end{array}$ & $\begin{array}{l}\text { ge gr } \\
\text { es E }\end{array}$ & $\begin{array}{l}\text { th of } \mathrm{re} \\
\text { countrie }\end{array}$ & $\begin{array}{l}\text { GDP } \\
\text { hat a }\end{array}$ & $\begin{array}{l}\text { capi } \\
\text { lso } \mathrm{m}\end{array}$ & $\begin{array}{l}\text { (1997-2 } \\
\text { nbers of }\end{array}$ & 5) & & \\
\hline
\end{tabular}

This paper focuses on the funding trade-offs associated with the two major stages of education, basic (K-12) and tertiary level and considers the following questions: How do governments and households allocate resources across different educational stages? How do private and public education expenditures interact, in the aggregate and at each stage? How can policy makers use this interaction to maximize the return on public spending? What are the implications of various educational public policies on the quality of human capital and consequently, on the growth rate of the economy?

To see the relevance of these questions, let us consider a salient comparison: education funding in the United States and the European Union. Table 1 reveals that public spending on education as a fraction of GDP is approximately the same in the two entities, while private spending is three times higher in the US than in the EU. Moreover, the allocation of resources across different education stages seems to differ widely. In particular, private resources in the US go overwhelmingly to tertiary education, while in the EU primary and secondary education prevail in allocation of private funding. While both US and European governments have allocated education resources similarly, households' spending on tertiary education is remarkably different.

In this paper we analyze the interactions and trade-offs that might be responsible for these outcomes. We use a stylized model of a hierarchical education system: a compulsory first stage (K-12) and an optional second stage (tertiary education). The model is used to analyze the growth-maximizing policy of public spending across stages, which takes into account the private incentives of individuals to invest in education.

We find that:

1) Consistent with data for OECD countries, the pursuit of growth-maximizing 
policies necessitates the share allocated to K-12 education to be predominant in the public spending on education, irrespective of the total public education budget size;

2) Maintaining strong public support for primary and secondary education increases the total household spending for education and more importantly, the share of private spending allocated to tertiary education. Interestingly, our results suggest that it is possible to increase both basic and tertiary education funding by using only the composition of the public budget to stimulate the private investment.

3) Increasing enrollment at the advanced stage of education does not always translate into higher growth, when it comes at the expense of decreasing the resources allocated to the basic stage;

4) Flat income tax levels have noticeable effects on the output growth rate as they affect the private incentives to invest in education ${ }^{3}$. In particular, an increase in taxes diminish the private resources allocated to education and bias their composition toward K-12 stage, where the return on investment is higher, due to enhanced complementarity between public and private spending. Consequently, growth-maximizing policies in a high-tax country imply a higher share of public spending allocated to higher education;

5) Given the difference in the tax levels in the US versus EU, our model supports an increase in the share of public funds allocated to K-12 in the US and enhanced public funding for tertiary education in the EU.

Our paper is related to the literature on growth and human capital accumulation. The differences in growth rates across developed economies have motivated a lot of debate on the role of education in fostering innovation and growth. Aghion et al. (2005), Sapir et al. (2003), Krueger and Lindahl (2001), Romer (2000) are just a few of the studies that address the relationship between human capital investment and growth. In particular, Aghion et al. (2005) use data for 50 US states to show that economies which are closer to the technological frontier benefit relatively more from investments in the advanced stages of education. While their result has important policy implications, we take the question further and ask how governments can optimally allocate resources across the education stages. Furthermore, we consider this question in the context of households' decision in response to the government allocation policy. The existing literature which studies the effects of changing the mix of education expenditures across K-12 and tertiary level has been mostly concerned with the allocation of either public or private spending across stages, with only limited attention given to the interaction between the two.

The literature considering education as a hierarchical process is small but rapidly growing. Driskill and Horowitz (2002) were the first to investigate the investment in hierarchical human capital in a dynamic setting. In their study of access to college

\footnotetext{
${ }^{3}$ In contrast, Lucas (1990), Stokey and Rebelo (1995), Glomm and Ravikumar (1998) find that taxes have negligible growth effects.
} 
education, Cardak and Givon (2004) use a static framework to analyze two extreme alternative public policies: making either pre-college schooling or college fully publicly funded. $\mathrm{Su}(2004)$ analyzes the dynamic implications of different allocations of public funds between basic and advanced education. She considers the case of private transfers as an extension. However, the setup used does not allow for the reallocation of the private resources across different stages or the interaction of private spending and the government allocation policy.

Restuccia and Urrutia (2004) consider the role of basic and college education in explaining the intergenerational persistence of earnings and the income inequality. Blankenau (2005) studies the optimal allocation of public spending across the two stages of the educational process. In his paper the basic stage is purely funded by public resources while the tuition in the advanced stage is partially funded by government subsidies. Kaganovich (2005) models the interaction between private and public spending in a mixed system of access to higher education (which recently emerged in Eastern Europe) featuring a two-track admission process: one that is tuition-free and based on academic performance and the second that charges full tuition, and is available to less prepared students. Consequently, households need to allocate their resources between pre-college preparation and/or payment for college. Finally, Blankenau et al. (2007) study how the allocation of a fixed education budget across K-12 education spending and college subsidies affects welfare and output.

In addition to the papers mentioned above, there is an abundant economic growth literature where public and private expenditures are inputs in a single stage human capital production (Glomm and Ravikumar (1992), Eckstein and Zilcha (1994), Glomm and Ravikumar (1998), Kaganovich and Zilcha (1999), Brauninger and Vidal (2000), Cassou and Lansing (2003), Bearse et al. (2005)).

This paper contributes to the literature by providing a simple model of hierarchical, two-stage education that incorporates both government funding policy and households' optimal decisions with respect to enrollment, overall education spending and its allocation across stages. Another contribution of the paper is that the process of hierarchical human capital formation is embedded in a general equilibrium model of a production economy which employs high and low skilled labor. The model appears to accomodate empirically relevant values for the elasticity of substitution between labor inputs of high-school and college graduates.

In our paper private education inputs are provided by parents as intergenerational altruistic transfers, rather than as self-financing by students 4 . Depending on the size and composition of the government budget for education, we find the optimal private inputs at each stage and describe how their relative sizes vary with the total level of private parental spending on education. Likewise, we analyze how enrollment in

\footnotetext{
${ }^{4}$ In Blankenau (2005), young agents take loans to finance the second stage of education, while the first stage is provided free of charge by the government.
} 
higher education responds to the size and structure of public allocations. As noted above, in addition to the public spending on education, the general tax level has an effect on both the quantity and quality of education acquired by households. Conversely, we study the growth maximizing educational policies when the government takes the households' reaction into account.

We analyze education provision in a highly aggregated model economy where agents differ only by educational status. Besides offering analytical tractability, this simplification enables us to circumvent modelling the institutional details that make the educational systems in various countries so different, and hence so difficult to fit in one analytical framework. To maintain generality, we assume, without going into institutional details, that education quality at each stage is produced by a technology that combines private and public inputs.

The degree of substitutability between private and public inputs in the various stages of education is of central importance to the issue analyzed. The literature has not reached a consensus on this matter. Thinking of these inputs exclusively as monetary transfers makes a strong case for perfect substitution. However, welfare and education public policies can have an impact, if any, at the early stages of child development rather than later ${ }^{5}$. If human capital investment is considered to include adequate child health care and nutrition, public spending might be a complement or a substitute to private spending for children from different income groups. Moreover, the public spending can be used in a variety of ways, from vouchers to public schools, subsidies to private schools or coordination and curricula improvement, each having potentially different effects on private resources devoted to education. Moreover, during K-12 education, most students live with their parents who support room and board expenditures while at the same time providing the so called "within the family" education (Nordblom (2003)). This strengthens the argument for complementarity during early education stages. Houtenville and Conway (2001) bring micro-level evidence in favor of substitutability at K-12 level when the private input considered is parental time. Kim (2001) finds on the other hand that while poor parents invest less in the child's human capital when public schooling increases, while rich parents instead increase their investment. At the aggregate level, Psacharopoulos and Patrinos (2004) show that social returns of primary education are significant in both developed and developing countries. The implied externalities suggest that public inputs might be good complements to private inputs in the production of primary and secondary education. Similar evidence is less compelling for tertiary education, as reviewed by Jacobs and van der Ploeg (2005). However, research activities, which are an important factor on the quality of tertiary education largely rely on public inputs. This might suggest less than perfect substitutability between private and

\footnotetext{
${ }^{5}$ See Cunha and Heckman (2007), Heckman and Masterov (2007), Carneiro and Heckman (2003) Heckman et al. (1999) LaLonde (1995).
} 
public inputs at this stage too.

Summing up the above arguments, it appears that the elasticity of substitution varies with the level of schooling, from low elasticities at early stages to high elasticity at later stages. In light of the above arguments, we consider a general specification of education technology where parameters are stage-specific, that allows for a constant elasticity of substitution (CES), similar to Bearse et al. (2005).

The paper is structured as follows. Section 2 presents the model. Section 3 contains the equilibrium analysis of a balanced growth path. Analytical results are derived for the case of perfect input substitutability in the higher education production. In Section 4 we study the effects of changes in the policy parameters on private resource allocations across the two educational stages and the growth rate of the economy. Section 5 relaxes the assumption of perfect substitution between private and public inputs and undertakes computational analysis of this more complex model. Section 6 looks at the growth-maximizing policies when government takes into account households' decision rules as functions of public policies parameters using the numerical results. Section 7 examines the tax level effects on the structure of both public and private education funding. Section 8 concludes. All proofs are in the Appendix A.

\section{The Model}

The economy is populated by a large number of identical households. Each period a household consists of a parent and a child, so that the population is constant over time. Each agent lives two periods, called youth and old age. Young agents (children) get educated in a hierarchical schooling system. When the agents are old, they give birth to offsprings, earn a wage specific to the human capital acquired in the first period, consume and make an educational transfers to their children. The size of each generation is normalized to one.

\subsection{Households}

\subsubsection{Child's educational problem}

The human capital formation is modeled as a two-stage process. The first stage is mandatory and corresponds to the primary and secondary education years (henceforth K-12 education). The second stage is optional and corresponds to tertiary education. Also, to accomplish it, people must give up an exogenous fraction $n_{2}$ of their adult working time. Since in most countries, education stages are quite standardized in duration, we set $n_{2}$ exogenously. The advanced stage training is pursued only by a part of the population, $\Pi_{t} \in(0,1)$. Thus, in equilibrium, a fraction of the young people will go to college and use the first stage education to increase their 
human capital. This is the skilled labor supply. Remaining workers will provide unskilled labor.

Similar to Blankenau (2005), each young agent has perfect foresight and chooses an education strategy taking the strategy of others as given, such that in equilibrium their behavior is consistent with the aggregate outcomes. Thus, a young agent at time $t$ chooses her probability of attending college $\pi_{t} \in[0,1]$, taking as given the proportion of college graduates in her generation $\Pi_{t} \in(0,1)$, market wages and public policies such that to be indifferent between the two choices. Consequently, the equilibrium $\pi_{t} \in[0,1]$ is given by the following indifference condition:

$$
\pi_{t}=\left\{\begin{array}{cl}
0 & ,\left(1-n_{2}\right) w_{2 t+1} h_{2 t}<w_{1 t+1} h_{1 t} \\
\in(0,1) & ,\left(1-n_{2}\right) w_{2 t+1} h_{2 t}=w_{1 t+1} h_{1 t} \\
1 & ,\left(1-n_{2}\right) w_{2 t+1} h_{2 t}>w_{1 t+1} h_{1 t}
\end{array}\right.
$$

where $w_{1 t+1}$ and $w_{2 t+1}$ are the next period unskilled and skilled wage per efficiency unit, $h_{1 t}$ and $h_{2 t}$ the human capital accumulated in the first and second stage, respectively. Since there is no uncertainty in college completion, we use the terms enrollment and attainment interchangeably.

The human capital in the first stage of education is produced using both privately and publicly provided inputs. The economic literature concerned with educational spending has used various specifications: Kaganovich and Zilcha (1999) use a CobbDouglas specification, implying an input elasticity of substitution equal to one. In Blankenau (2005), public and private inputs are complements in the human capital production function at the first stage and perfect substitutes in the production of tertiary education. Glomm and Kaganovich (2003) use an additive specification to model the relationship between education provision and social security.

Since the focus of this paper is on the interaction between public and private spending, we do not consider other factors that play a role in human capital production, such as the stock of human capital accumulated by the previous generation or parental time. However, including these factors does not alter the main conclusions of the paper. The human capital acquired in the first stage by a young agent at time $t$ is given by the following production function:

$$
h_{1 t}=B_{1}\left[\rho e_{1 t}^{-\gamma_{1}}+(1-\rho) b_{1 t}^{-\gamma_{1}}\right]^{-\frac{1}{\gamma_{1}}}
$$

where $e_{1 t}$ and $b_{1 t}$ are the public and private inputs per student, $\gamma_{1} \in[-1,+\infty)$, $0<\rho<1$ and $B_{1}>0$.

The human capital of a college educated agent is then produced according to:

$$
h_{2 t}=B_{2} h_{1 t}^{\theta}\left[e_{2 t}^{-\gamma_{2}}+b_{2 t}^{-\gamma_{2}}\right]^{-\frac{1-\theta}{\gamma_{2}}},
$$


where where $e_{2 t}$ and $b_{2 t}$ are the public and private inputs per student, $\gamma_{2} \in[-1,+\infty)$, $0<\theta<1$ and $B_{2}>0$. The human capital accumulated in the first stage $\left(h_{1 t}\right)$ is an essential input in the production of tertiary education, by the very nature of the educational process. We explore the strength of this complementarity in Appendix C by extending the production function in (3) to a CES specification. The coefficient $\theta$ shows how important knowledge acquired during K-12 studies is for success in tertiary education. If $\gamma_{2}=-1$, public and private inputs are perfect substitutes. In line with the discussion in the introduction, we expect private and public inputs to be better (potentially perfect) substitutes in tertiary education compared to earlier stages of education.

Assumption 1. $-1 \leqslant \gamma_{2} \leqslant \gamma_{1}$.

Notice that for $\gamma_{1}, \gamma_{2} \in[-1,0)$, public inputs are not essential in the production of human capital.

To keep the model tractable, we abstract from the interaction between the child and parent in financing the cost of college, by assuming all private inputs are provided by parents.

In order to analytically derive the main results and policy implications of the model, we first focus on particular cases of human capital production functions. We initially assume a Cobb-Douglas education production function instead of the more general CES form. This implies $\gamma_{1}=0$ and

$$
h_{1 t}=B_{1} e_{1 t}^{\rho} b_{1 t}^{1-\rho}
$$

This specification has been frequently used in the literature studying human capital accumulation (see for example Blankenau (2005), $\mathrm{Su}(2004)$ ). Furthermore, for the higher education production function, we first assume perfect elasticity of substitution, or $\gamma_{2}=-1$. Thus, similarly to Glomm and Kaganovich (2003), we have:

$$
h_{2 t}=B_{2} h_{1 t}^{\theta}\left[e_{2 t}+b_{2 t}\right]^{1-\theta},
$$

We use this special case as a starting point in order to illustrate the mechanisms at work in the model. We relax the assumption of $\gamma_{1}=0$ and $\gamma_{2}=-1$ in Section 5 .

\subsubsection{Parent's educational spending decisions}

The parents allocate a portion of their income to educational transfers. The overall amount of parental resources spent on education depends on income and stems from an altruistic motive. Ex-ante, each offspring decides to attend college with probability $\pi_{t}$. Given perfect foresight, this corresponds to an ex-post measure $\pi_{t}=\Pi_{t}$ of college educated individuals in the economy. Parents will allocate the transfers across the two stages in order to maximize the expected utility derived from the human capital accumulated by their children. 
Denote the share of household's disposable income allocated for educational purposes $\Delta_{t}$ and the fraction dedicated to K-12 education as $\psi_{t}$. Then the amount spent at each stage is given by:

$$
\begin{aligned}
& x_{1 t}=\psi_{t} \Delta_{t} Y_{t}(1-\tau), \\
& x_{2 t}=\left(1-\psi_{t}\right) \Delta_{t} Y_{t}(1-\tau) .
\end{aligned}
$$

where $\tau$ is the constant income tax rate.

Formally, the parent's problem is

$$
\begin{aligned}
\max _{\left\{c_{t}, b_{1 t}, b_{2 t}\right\}} U= & \ln c_{t}+\mu\left[\left(1-\pi_{t}\right) \ln h_{1 t}+\pi_{t} \ln h_{2 t}\right] \quad \text { s.t. } \\
c_{t}+x_{1 t}+x_{2 t}= & (1-\tau) w_{t} h_{t-1}, \\
& \text { (4), (5), (6) and (7) } \\
& \text { given } \tau, \pi_{t}, e_{1 t}, e_{2 t}
\end{aligned}
$$

where $c_{t}$ represents parent's consumption, $w_{t}$ is the wage per efficiency unit at time $t$ and $h_{t-1}$ the parental human capital accumulated in the previous period. The wage income is taxed at a constant rate $\tau$. The parameter $\mu \geq 0$ captures the utility weight the parent attaches to child's human capital. Recall that agents have the same life time income after the educational choice is made, as given by the indifference condition (1).

The private investment in basic education is certain and it enters the utility function directly through $h_{1 t}$ (with probability $1-\pi_{t}$ ) and through $h_{2 t}$ which is also a function of $h_{1 t}$ (with probability $\pi_{t}$ ). Therefore, the private input per student in the production technology of basic education $b_{1 t}$ is equal to $x_{1 t}$.

On the other side, the private investment in higher education is the price of a lottery ${ }^{6}$ that earns the child a college degree with probability $\pi_{t}$. Ex-post, private investment per capita among the measure $\pi_{t}$ of successful college candidates is:

$$
b_{2 t}=\frac{x_{2 t}}{\pi_{t}}
$$

The parent needs to choose jointly the level of education spending as a fraction of disposable income $\left(\Delta_{t}\right)$ and the fraction of resources devoted to each educational

\footnotetext{
${ }^{6}$ The view of higher education as a lottery is motivated by considerable college drop-out rates. The OECD average survival rate in tertiary education was $70 \%$ in 2004 (OECD (2006)). It varies between $53 \%$ in Mexico and $91 \%$ in Japan.
} 
stage $\left(\psi_{t}, 1-\psi_{t}\right)$. We use the budget constraint, (6) and (7) to rewrite the parent's problem at time $t$ :

$$
\begin{aligned}
\max _{\left\{\Delta_{t}, \psi_{t}\right\}} U= & \ln \left[(1-\tau)\left(1-\Delta_{t}\right) w_{t} h_{t-1}\right]+ \\
& \mu\left[\left(1-\pi_{t}\right) \ln h_{1 t}\left(\Delta_{t}, \psi_{t}\right)+\pi_{t} \ln h_{2 t}\left(\Delta_{t}, \psi_{t}\right)\right] \\
& \text { s.t. (4) and (5) }
\end{aligned}
$$

Taking the first order conditions with respect to $\left(\Delta_{t}, \psi_{t}\right)$ yields the following expressions:

$$
\begin{gathered}
\left(\Delta_{t}\right): \frac{-1}{1-\Delta_{t}}+\mu\left[\left(1-\pi_{t}\right) \frac{1}{h_{1 t}} \frac{\partial h_{1 t}}{\partial \Delta_{t}}+\pi_{t} \frac{1}{h_{2 t}} \frac{\partial h_{2 t}}{\partial \Delta_{t}}\right] \leqslant 0,=0 \text { if } \Delta_{t} \in(0,1) \\
\left(\psi_{t}\right):\left(1-\pi_{t}\right) \frac{1}{h_{1 t}} \frac{\partial h_{1 t}}{\partial \psi_{t}}+\pi_{t} \frac{1}{h_{2 t}} \frac{\partial h_{2 t}}{\partial \psi_{t}} \gtreqless 0 \\
=0 \text { if } \psi_{t} \in(0,1),<0 \text { if } \psi_{t}=0,>0 \text { if } \psi_{t}=1
\end{gathered}
$$

\subsection{Production sector}

A representative firm uses the two types of human capital to produce the final output:

$$
Y_{t}=A\left(\gamma H_{1 t-1}^{-\eta}+(1-\gamma) H_{2 t-1}^{-\eta}\right)^{-\frac{1}{\eta}}
$$

where $A$ is the total factor productivity, $\eta \in[-1, \infty)$ and $0<\gamma<1$. In order to derive analytical results we first specialize production to the Cobb-Douglas functional form

$$
Y_{t}=A H_{1 t-1}^{\gamma} H_{2 t-1}^{1-\gamma}
$$

while in the later sections we present the general model using the CES specification. The assumption has nontrivial implications for the size of enrollment in higher education as we shall see in the Section 5.

The aggregate supplies of unskilled and skilled labor are given by the following expressions:

$$
\begin{gathered}
H_{1 t-1}=\left(1-\Pi_{t-1}\right) h_{1 t-1}, \\
H_{2 t-1}=\left(1-n_{2}\right) \Pi_{t-1} h_{2 t-1} .
\end{gathered}
$$




\subsection{Government}

The government taxes income at a constant rate $\tau$ and uses a fraction of the tax revenues to provide public inputs in both stages of the education process. Denote the share of income that goes to public education as $g, g<77$. The education budget is balanced so that

$$
g Y_{t}=E_{t}=e_{1 t}+\Pi_{t} e_{2 t}
$$

Denote by $\phi_{t}$ the fraction of the total public spending devoted to K-12 level. Consequently, the per capita allocations for K-12 and tertiary education are given by the following expressions:

$$
\begin{aligned}
e_{1 t} & =\phi_{t} E_{t}=\phi_{t} g Y_{t}, \\
e_{2 t} & =\frac{1-\phi_{t}}{\Pi_{t}} E_{t}=\frac{1-\phi_{t}}{\Pi_{t}} g Y_{t} .
\end{aligned}
$$

\section{Equilibrium analysis}

We first define a competitive equilibrium in an economy where policies $\left\{\tau, g, \phi_{t}\right\}$ are exogenous.

Definition 1. An equilibrium with exogenous public policies is defined as a triplet $\left\{\pi_{t}, \Delta_{t}, \psi_{t}\right\}$ such that, at the beginning of each time period $t$ :

1. The young agent chooses the probability to attend college $\pi_{t}$ such that to satisfy (1), given the aggregate measure of college educated agents $\Pi_{t}$, wages $w_{1 t}$ and $w_{2 t}$, parental allocations $b_{1 t}, b_{2 t}$ and governmental outlays $e_{1 t}, e_{2 t}$ for education across the two stages;

2. Individual and aggregate decisions are consistent in equilibrium: $\pi_{t}=\Pi_{t}$;

3. Given the wages, $\pi_{t}, \Pi_{t}$, and the government policies, the allocations $\left\{\Delta_{t}, \psi_{t}\right\}$ solve the parent's problem (8);

4. The firms pay competitive market wages;

5. The educational public budget is balanced.

\subsection{Optimal enrollment}

To find the equilibrium enrollment $\Pi_{t}$, we use (1). The production function satisfies the Inada condition with respect to both inputs. This guarantees that in equilibrium

\footnotetext{
${ }^{7}$ Given the paper focuses on analyzing the interaction between private and public provision of education, we do not model the usage of the remaining revenues, $\tau-g$. This share can be thought of as a waste or unproductive government consumption.
} 
$\pi_{t}$ is strictly between zero and one. A corner solution of zero (one) would drive the wage for skilled (unskilled) labor to positive infinity, which in turn would make the choice for $\pi_{t}$ unsustainable. The equilibrium probability to attend college is derived from the indifference condition:

$$
\left(1-n_{2}\right) w_{2 t+1} h_{2 t}=w_{1 t+1} h_{1 t}
$$

Plugging in the competitive wages

$$
w_{1 t+1}=\gamma \frac{Y_{t+1}}{H_{1 t}}, w_{2 t+1}=(1-\gamma) \frac{Y_{t+1}}{H_{2 t}},
$$

and using the supply definitions (13) and (14), (18) yields a constant enrollment

$$
\Pi_{t}=\Pi=1-\gamma, \forall t>0 \text {. }
$$

Consequently, the fraction of skilled people equals the fraction of the skilled labor wage bill in total income. The constant enrollment is a feature derived from the Cobb-Douglas assumption on the output production. We show in Section 5 that in the general case of CES production, enrollment is a function of the relative stocks of skilled and unskilled labor and therefore varies with both the policy variables and households allocations.

\subsection{The balanced growth path}

We look for a balanced growth path equilibrium, where the output and both types of human capital grow at a common, constant rate $g_{y}$ and the shares $\left\{\Delta_{t}, \psi_{t}, \phi_{t}\right\}$ are constant.

Plugging the expressions for $e_{1 t}, e_{2 t}, b_{1 t}$ and $b_{2 t}$ into (2) and (5) and using the fact that agents are homogenous within the skill group (i.e. $h_{1 t}$ and $h_{2 t}$ are the same for all agents), we get the following expressions for human capital accumulated in the first and second stage, respectively:

$$
\begin{aligned}
h_{1 t}= & B_{1}(\phi g)^{\rho}[\psi \Delta(1-\tau)]^{1-\rho} Y_{t} \\
h_{2 t}= & B_{2}\left\{(\phi g)^{\rho}[\psi \Delta(1-\tau)]^{1-\rho}\right\}^{\theta} \frac{1}{\Pi^{1-\theta}} \times \\
& {[(1-\phi) g+(1-\psi) \Delta(1-\tau)]^{1-\theta} Y_{t} }
\end{aligned}
$$

Combining (12), (13), (14) and using $\Pi_{t-1}=\Pi_{t}$, we get

$$
Y_{t}=A(1-\Pi)^{\gamma}\left[\Pi\left(1-n_{2}\right)\right]^{1-\gamma} h_{1 t-1}^{\gamma} h_{2 t-1}^{1-\gamma},
$$


Using (20) and (21) in 12 we get the growth rate of the economy:

$$
\begin{aligned}
g_{y}= & \frac{Y_{t}}{Y_{t-1}}=C\left\{(\phi g)^{\rho}[\psi \Delta(1-\tau)]^{1-\rho}\right\}^{\gamma+\theta(1-\gamma)} \times \\
& {[(1-\phi) g+(1-\psi) \Delta(1-\tau)]^{(1-\theta)(1-\gamma)}, }
\end{aligned}
$$

where $C=A B_{1}^{\gamma} B_{2}^{1-\gamma}(1-\Pi)^{\gamma} \Pi^{\theta(1-\gamma)}\left(1-n_{2}\right)^{1-\gamma}$.

\subsection{Equilibrium spending allocations}

We solve for household decisions as functions of public policy parameters on the balance growth path, so that $\Delta_{t}=\Delta$ and $\psi_{t}=\psi$. Proposition 1 provides the condition under which an interior solution for the fraction of the household's education budget allocated to K-12 education $\psi$ exists. All proofs are in the Appendix.A

Proposition 1. There exists a threshold $\widetilde{\Delta}=\frac{(1-\rho)[1-\Pi(1-\theta)](1-\phi) g}{\Pi(1-\theta)(1-\tau)}$ such that $\psi=\frac{(1-\rho)[1-\Pi(1-\theta)]}{1-\rho[1-\Pi(1-\theta)]}\left\{\frac{(1-\phi) g}{\Delta(1-\tau)}+1\right\} \in(0,1)$ if $\Delta>\widetilde{\Delta}$ and $\psi=1$ otherwise.

In other words, households tend to invest privately in higher education only if they spend a high fraction of their income on education overall. They are more likely to do so if they have a larger disposable income ( $\tau$ lower), or the total public spending in education $g$ and the fraction of it devoted to higher education $(1-\phi)$ are sufficiently low. Also, the more important the private input is in the human capital production in the first stage (i.e. the greater the parameter $1-\rho$ ), the lower the likelihood of private investment in the second stage. The opposite holds for the elasticity of spending per student $(1-\theta)$ in the production of human capital in the advanced stage.

The fraction of private resources allocated to the advanced education stage is increasing in the total amount of private contributions. This is an important intermediate result since it highlights the fact that all factors (including policy variables) that make the households richer will generate higher private spending in tertiary education.

Proposition 2. $\mu>\frac{g(1-\phi)}{\Pi(1-\theta)(1-\tau)-g(1-\phi)(1-\rho)[1-\Pi(1-\theta)]}$ is a sufficient 
and necessary condition for $\psi \in(0,1)$. Then,

$$
\begin{aligned}
& \Delta_{t}=\Delta=\frac{\mu(1-\tau)\{1-\rho[1-\Pi(1-\theta)]\}-g(1-\phi)}{(1-\tau)\{1+\mu\{1-\rho[1-\Pi(1-\theta)]\}\}} \text { and } \\
& \psi_{t}=\psi=\frac{\mu(1-\rho)[1-\Pi(1-\theta)][1-\tau+g(1-\phi)]}{\mu(1-\tau)\{1-\rho[1-\Pi(1-\theta)]\}-g(1-\phi)} .
\end{aligned}
$$

Otherwise,

$$
\Delta_{t}=\frac{\mu(1-\rho)[1-\Pi(1-\theta)]}{1-\mu(1-\rho)[1-\Pi(1-\theta)]} \text { and } \psi_{t}=1 .
$$

Since public inputs enter the production of human capital in both stages, private resources are not essential, so the households will allocate private resources for tertiary education only if the altruism coefficient is strong enough, as suggested above.

Assuming interior solutions for $\Delta$ and $\psi$, we perform the following policy experiments: we change the generosity of total public spending on education $g$, the public spending mix $\phi$ and the tax rate $\tau$ in order to analyze their effects on both $\Delta$ and $\psi$.

\section{Policy experiments}

In this section, we briefly describe the main analytical results of the model for the case $\gamma_{1}=0, \gamma_{2}=-1$ and Cobb-Douglas production function $(\gamma=0)$. In the following sections, we develop the analysis and the policy implications in a more general setup that is calibrated and solved numerically.

Proposition 3. (A change in the generosity of public spending g) Assume $\Delta, \psi \in$ $(0,1)$ and a fixed $\phi \in(0,1)$. Then $\frac{\partial \Delta}{\partial g}<0$ and $\frac{\partial \psi}{\partial g}>0$.

An increase in the total public budget for education $(g)$ has a negative effect on the overall level of private spending on education. It also leads to a higher fraction of total private spending allocated to the first educational stage. Given a fixed fraction $\phi$ of public resources allocated to K-12 stage, a higher budget $g$ implies more public spending in both stages. The complementarity from the first stage between private and public resources is dominated by the substitution effect in the second stage. Since the overall level of human capital increases with $g$, its marginal utility decreases, hence $\Delta$ goes down.

The second result indicates that at a given level of educational private spending $\Delta$, the share allocated to first stage education increases with $g$ since higher public inputs boost the productivity of private inputs in K-12 but not in tertiary education. Thus agents substitute towards the more productive use of their resources. 
Proposition 4. A change in the public spending mix $(\phi)$. Assume $\Delta, \psi \in(0,1)$ and a fixed $g \in(0,1)$. Then $\frac{\partial \Delta}{\partial \phi}>0$ and $\frac{\partial \psi}{\partial \phi}<0$.

Assuming the level of public funding for education is fixed, a higher share of K12 public funding generates an increase in total private spending in education and hence higher private contributions at both stages. Secondly, an increase in public K-12 spending prompts households to allocate a larger share of their investments towards higher education.

Propositions 3 and 4 are particularly important. Households respond to both the size $(g)$ and the composition $(\phi)$ of public education budget. In the context of policy making, governments have two alternative ways to expand higher education provision given a fixed level of public resources $g$. First, they could directly decrease $\phi$ or on the contrary, increase their participation in the basic stages and let households use more of their resources in the advanced stage. We expand on the policy implications in the next sections. Moreover, chanelling more resources towards the basic stage has the interesting effect of increasing the overall education spending in the economy as it boosts the private investment in human capital.

Complementarity between public and private inputs in K-12 education is instrumental in obtaining this result. A higher share of K-12 public inputs produces two effects on $\psi$. Since $\phi$ goes up, $1-\phi$ must go down, which implies that less public inputs are available in the second stage, since the size of the public budget $g$ is fixed. Households will compensate this decrease by decreasing $\psi$. This is the direct effect. Second, an increase in $\phi$ raises the marginal productivity of private resources in the first stage. This would prompt an increase in the total private spending $\Delta$ which in turn leads to a decrease in $\psi$. It can be seen that the effects on $\psi$ reinforce each other, such that in equilibrium $\psi$ will decrease.

However, private investment in education depends on many other factors. In particular, notice that $\Delta$ also depends on the general tax level, $\tau$, so differences in taxation undoubtedly explain why private contributions vary a lot across economies. Thus, it is useful to establish the following results.

Proposition 5. A change in the income tax rate $(\tau)$. Assume $\Delta, \psi \in(0,1)$. Then for given $\phi, g \in(0,1), \frac{\partial \Delta}{\partial \tau}<0$ and $\frac{\partial \psi}{\partial \tau}>0$.

Higher tax rates lead to a lower disposable income and consequently diminish the private incentives to invest in education at all stages. Interestingly, in the same time, higher taxes produce a reallocation of private resources towards the first stage, where scarcer private resources yield higher human capital and hence higher utility. Section 7 expands on this aspect. 


\section{The general model}

The case $\gamma_{1}=0$ and $\gamma_{2}=-1$ was considered for analytical tractability. However, a more general analysis seems to be warranted given the scant and ultimately inconclusive empirical evidence on the estimates of such elasticities for education production functions. While the education literature reviewed above does not imply any particular values for $\gamma_{1}$ and $\gamma_{2}$, it does suggest that the elasticity of substitution between private and public inputs is higher in the first stage compared to the second. In a somewhat related exercise, Clotfelter (1977) analyzes the role of substitution between private and public inputs in the production of law and order. He estimates a production function of security that is CES in private and public inputs. He finds an elasticity of 2.47 , while perfect substitution would imply a value of plus infinity. This illustrates the fact that in reality, public and private inputs are often quite far from being perfect substitutes.

In the following, we relax the assumptions on the functional form of human capital production in both stages. We also allow the final good production to combine skilled and unskilled labor at a constant elasticity of substitution:

$$
Y_{t}=A\left(\gamma H_{1 t-1}^{-\eta}+(1-\gamma) H_{2 t-1}^{-\eta}\right)^{-\frac{1}{\eta}}
$$

This assumption extends the model in an important way. While the Cobb-Doublas form implied a constant enrollment $\Pi=1-\gamma$, the CES form will generate a policy dependent enrollment. Since the general setup does not yield analytical results, we calibrate the model and solve it numerically.

With the CES specification, market wages are given by:

$$
\begin{aligned}
& w_{1 t}=\frac{Y_{t}}{H_{1 t-1}} \frac{\gamma H_{1 t-1}^{-\eta}}{\gamma H_{1 t-1}^{-\eta}+(1-\gamma) H_{2 t-1}^{-\eta}}, \text { and } \\
& w_{2 t}=\frac{Y_{t}}{H_{2 t-1}} \frac{(1-\gamma) H_{2 t-1}^{-\eta}}{\gamma H_{1 t-1}^{-\eta}+(1-\gamma) H_{2 t-1}^{-\eta}} .
\end{aligned}
$$

Substituting the labor market clearing conditions (13) and (14) we obtain that enrollment is given by

$$
\frac{1-\Pi_{t}}{\Pi_{t}}=\left(\frac{\gamma}{1-\gamma}\right)^{\frac{1}{1+\eta}}\left(\left(1-n_{2}\right) \frac{h_{2 t-1}}{h_{1 t-1}}\right)^{\frac{\eta}{1+\eta}} .
$$

Further, on a balanced growth path, we can use the equilibrium solutions for the 
human capital in the two stages

$$
\begin{aligned}
& h_{1 t-1}=B_{1} Y_{t}\left[\rho(\phi g)^{-\gamma_{1}}+(1-\rho)(\psi \Delta(1-\tau))^{-\gamma_{1}}\right]^{-\frac{1}{\gamma_{1}}}, \text { and } \\
& h_{2 t-1}=B_{2} h_{1 t-1}^{\theta} Y_{t}^{1-\theta}\left[\left(\frac{(1-\phi) g}{\Pi_{t}}\right)^{-\gamma_{2}}+\left(\frac{(1-\psi) \Delta(1-\tau)}{\Pi_{t}}\right)^{-\gamma_{2}}\right]^{-\frac{1-\theta}{\gamma_{2}}}
\end{aligned}
$$

to substitute into (28). To do this, it is useful to rewrite

$$
\begin{aligned}
\frac{h_{2 t-1}}{h_{1 t-1}}= & \Pi_{t}^{\theta-1} B_{2} B_{1}^{\theta-1}\left[\rho(\phi g)^{-\gamma_{1}}+(1-\rho)(\psi \Delta(1-\tau))^{-\gamma_{1}}\right]^{-\frac{\theta-1}{\gamma_{1}}} \times \\
& {\left[((1-\phi) g)^{-\gamma_{2}}+((1-\psi) \Delta(1-\tau))^{-\gamma_{2}}\right]^{-\frac{1-\theta}{\gamma_{2}}} }
\end{aligned}
$$

Upon substitution (28) becomes independent of the output level. Therefore, on a balanced growth path, the enrollment level is constant and given by the solution of the following nonlinear equation

$$
\chi \Pi^{\frac{1-\eta(1-\theta)}{1+\eta}}=1-\Pi,
$$

where $\chi=\left(\frac{\gamma}{1-\gamma}\right)^{\frac{1}{1+\eta}}\left(\begin{array}{c}\left(1-n_{2}\right) B_{2} B_{1}^{\theta-1}\left[\rho(\phi g)^{-\gamma_{1}}+(1-\rho)(\psi \Delta(1-\tau))^{-\gamma_{1}}\right]^{\frac{1-\theta}{\gamma_{1}}} \times \\ {\left[((1-\phi) g)^{-\gamma_{2}}+((1-\psi) \Delta(1-\tau))^{-\gamma_{2}}\right]^{-\frac{1-\theta}{\gamma_{2}}}}\end{array}\right)^{\frac{\eta}{1+\eta}}$.

It is easy to check that equation $(29)$ has a unique positive solution $\Pi \in(0,1)$. To further explore the predictions of the generalized setup, we parametrize the model as follows.

In the model a period is approximately 30 years, so $n_{2}=0.13$ matches the average duration of tertiary education of about 4 years. We set the public spending share in GDP, $g$ and the K-12 share of public spending, $\phi$, at the 2003 OECD average of $5.54 \%$ and $76 \%$ respectively. Similarly, $\tau$ is set to $36 \%$, the average total tax receipts as a percentage of GDP in OECD.

We choose the total factor productivity $A$ to obtain an annual growth rate of approximately $2 \%$. This corresponds to a per period growth factor of 1.8 . $B_{1}$ is normalized to one and $B_{2}$ is set such that human capital of the college educated remains higher than that of high-school educated even when all public funds are used in $\mathrm{K}-12$.

We choose $\eta=-0.35$ to yield an elasticity of substitution between skilled and unskilled labor of $1.54^{8}$. The output share of unskilled labor, $\gamma$ is set to $0.65^{9}$.

\footnotetext{
${ }_{8}^{8}$ Caucutt and Kumar (2003) use a similar value. Krusell et al. (2000) estimate an elasticity of about 1.6 in a CES production function with physical capital.

${ }^{9}$ Estimates for the share of unskilled labor used in the literature vary from 0.8 (Blankenau et al.
} 
We assume equal productivity for the public and private spending in the first stage, which implies $\rho=0.5$. The weight of K-12 education in the production of tertiary education $\theta$ is fixed at 0.2 . This low weight reflects the fact that while knowledge acquired during K-12 studies serves as foundation for later education, it is nonetheless basic and not often used as such by skilled workers. For example, engineers rarely use Pythagora's theorem. We perform a sensitivity analysis for this parameter in Appendix B .

Given the above parameters for the public policies, we set $\gamma_{2}, \gamma_{1}$ and $\mu$, the altruism parameter, to obtain values for $\Delta$ (share of private spending in disposable income), $\psi$ (K-12 share of private spending), and $\Pi$ (higher education enrollment) that are consistent with data on education finance and attainment in the OECD countries.

However, private investment in human capital, especially in the first stage is difficult to measure (e.g.: nutrition, health-care, "within the family education") and therefore more likely to be under-reported. Keeping this in mind, we interpret the observed values of the private spending, $\Delta$, and the private $\mathrm{K}-12$ share, $\psi$, as lower bounds for our calibration. The same argument applies for the college attainment. In this paper we do not allow for uncertainty in college completion (see Restuccia and Urrutia (2004), Caucutt and Kumar (2003)). Therefore, the enrollment rate $\Pi$ is equal to the attainment rate, defined as the share of college educated people in the labor force.

Thus, $\mu=0.06, \gamma_{1}=-0.4$ and $\gamma_{2}=-0.8$ yield a private spending share in $\operatorname{GDP}\left(\frac{\Delta}{1-\tau}\right)$ of $1.17 \%$, a K-12 share in the private spending $(\psi)$ of $85.3 \%$ and an attainment rate $(\Pi)$ of $34.62 \%$. The value of $\frac{\Delta}{1-\tau}$ for the OECD countries varies between $0.13 \%$ (Turkey) to $3.01 \%$ (Korea), with an OECD average share of $0.94 \%$. The observed OECD averages for $\psi$ and $\Pi$ are $52.3 \%$ and $25 \%$ respectively. Appendix B gives a summary of the calibration and a sensitivity analysis for $\gamma_{1}$ and $\gamma_{2}$.

Figure 1 describes the changes in the variables of interest when public policies are varied exogenously.

We begin by analyzing the effects of $\phi$ on household decisions and aggregate outcomes. The graphs in the top row of Figure 1 show the households allocations $\Delta, \psi$ and $\Pi$ and the growth rate of the economy $g_{Y}$ for $\phi \in[25,100]$ and $g$ fixed at the OECD average.

Public resources substitution from tertiary toward K-12 education is facilitated by the different per capita effects of these resources. At the advanced stage, a given amount of public resources has a higher productivity than in the first stage since only a measure $\Pi<1$ of people attend college. As stated in Proposition 4, a (2007)) to 0.5 (Caucutt and Kumar (2003)). 

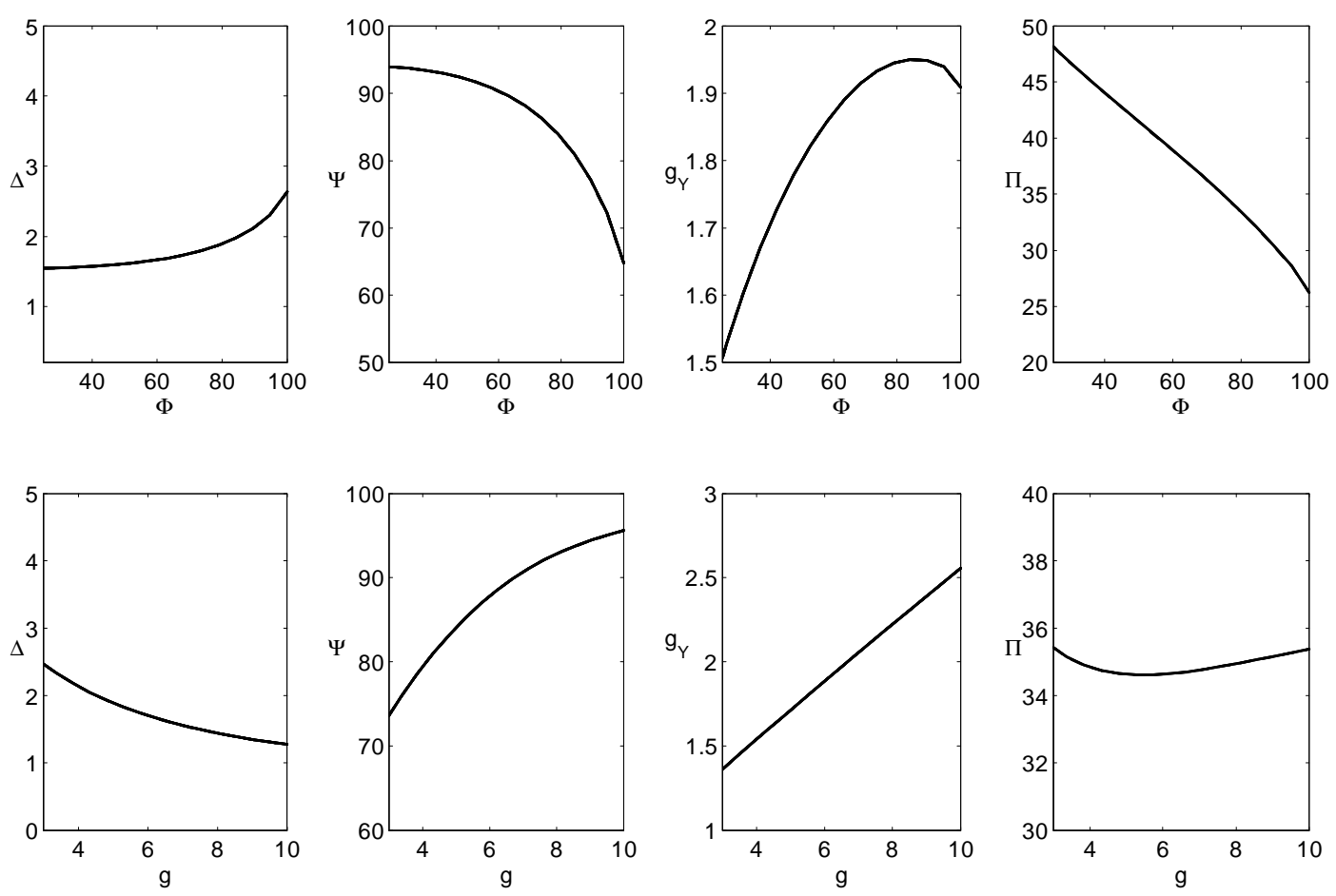

Figure 1: Exogeneous policies in the benchmark model. First row: $g=5.54 \%$; Second row: $\phi=76 \%$.

higher share of public resources allocated to K-12 education induces two households reactions. First, they provide more private educational inputs, which results in a higher overall share of educational investment in disposable income (higher $\Delta$ ), and hence more human capital of both types. This has a positive effect on growth rate. Second, they allocate a higher share of the increased education budget on advanced education. However, shifting public resources towards basic education lowers the quality of tertiary education and therefore has a negative effect on attainment in the advanced education stage.

While dynamic complementarity between early and late investment in human capital has been analyzed in the literature (Cunha and Heckman (2007), Restuccia and Urrutia (2004)), here we analyze a double complementarity: in timing and in the source of spending. The last interaction, between private and public resources, highlights an additional role for education policy: to stimulate and direct the private spending across education stages. As less public funding is available for tertiary education (since the size of the budget is fixed), its quality decreases, since households do not fully replace this spending. The partial crowding-in decreases the enrollment 
and ends up hurting the growth rate of the economy. Interestingly, the growth maximizing share of public K-12 spending is around $80 \%$, close to the observed values for the OECD countries.

Summing up, the analysis yields two main conclusions: (1) an increased share of public funds in the first stage will have a non-monotonic effect on the growth rate but (2) will also decrease the share of skilled people in the economy. In other words, we find that focusing on higher education may pay off in terms of growth when the amount allocated to higher education is low. Budgeting even more funds to the second stage will increase indeed college attainment but at the expense of economic growth. These conclusions are particularly relevant in light of recent efforts to expand higher education in both developed and developing countries as a way to support a knowledge-based economy and ultimately to maintain steady growth rates.

We now move on to analyze the effects of changing the budget size. In the graphs in the second row of Figure 1, $\phi=76 \%$ while the educational public budget $g$ varies between $3 \%$ and $10 \%$ of GDP. The OECD countries invest between 3.5\% (Greece) and $8 \%$ (Denmark) of GDP in education. The results stated in Proposition 3 hold. Households reduce their education budget and in the same time direct a higher share of this budget toward K-12 education. However, as more public resources flow into both stages, human capital of skilled and unskilled workers keeps increasing and so does the growth rate. In our model the education budget $g$ is always lower then the tax rate $\tau$. Thus, on the relevant ranges for $g$ and $\tau$, the economy is on the upward sloping side of the Laffer curve - where an increase in $g$ increases the growth rate.

While more public funding increases both types of human capital, resources are more effective in the advanced than in the basic education, since they are allocated to a smaller student population. Therefore, human capital of college graduates increases faster than that of the high-school graduates. Recall that skilled and unskilled workers are rather good substitutes, so the relative increase in college type human capital triggers a decrease in their relative wage and also in enrollment. At even higher education budgets, the increase in human capital dominates the decrease in the wage, so the enrollment goes up.

Somewhat complementary to the previous results, we can now state that, keeping the allocation of the budget fixed (1) bigger public spending for education generates higher growth rates but (2) not necessarily higher enrollment in tertiary education.

Up so far we have considered separately the effects of changing the structure and the size of the public budget for education. Tertiary education enrollment and output growth are high priority policy objectives and often the former is seen as a precondition for the latter. Our model helps to explain when this may or may not be the case. On the other side, if we assume that governments can use both the size and the structure of the education budget as policy tools, the analysis above shows that maximum growth and enrollment can be attained. However, political 
economy considerations (such as electoral concerns or a higher degree of unionization in primary and secondary education sector) can imply different abilities to control these instruments. In the next section, we focus on a subset of policy targets and instruments, by assuming governments set the K-12 share of public spending such that to maximize the output growth rate.

\section{Growth maximizing policies}

Recall that due to constant returns in the production of output and human capital, in equilibrium, the model generates balanced growth in output, denoted by $g_{y}$. We assume the government's objective is to maximize the steady-state growth rate of output by choosing the fraction of educational resources invested in K-12 education $\phi$, given the general tax level $\tau$ and the size of the overall education budget $q^{10}$. Thus, the government takes into account the reaction function of households to public policies $\Delta(\phi, g), \psi(\phi, g)$ and $\pi(\phi, g)$ when it chooses $\phi$, while households take the public educational policies as given. Formally, the government problem is stated as follows:

$$
\begin{gathered}
\max _{\{\phi\}} g_{y}(\phi, g) \quad \text { s.t. } \\
g Y_{t}=E_{t}=e_{1 t}+\Pi_{t} e_{2 t} \\
\text { given } \tau, g, \psi(\phi, g), \Delta(\phi, g), \\
\text { where } \psi(\phi, g) \text { and } \Delta(\phi, g) \text { solve }(8) \text { and } \pi(\phi, g)=\Pi
\end{gathered}
$$

We solve for the optimal $\phi$ numerically using the parametrization described in the previous section.

Figure 2 shows the growth-maximizing $\phi$ and the corresponding households' decisions, $\psi$ and $\Delta$, as well as the growth rate of the economy $g_{Y}$ and the enrollment $\Pi$.

As previously discussed, public spending is more productive in tertiary education than it is in K-12, due to the "per capita" effect. An extra dollar spent in tertiary education applies to a measure $\Pi<1$ students rather than the entire population (of measure 1) if spent on K-12 education. Thus, everything else constant, at low levels

\footnotetext{
${ }^{10}$ It makes sense to consider $g$ as fixed, since on the relevant range, higher $g$ always implies a higher growth rate. Moreover, the size of the public budget allocated to education reflects political preferences that are quasi fixed for a specific country and depend on many factors among which the degree of unionization in education, the size of private education sector, level of development etc. In the same spirit, the general tax level can be considered the result of a political process, not modelled here.
} 

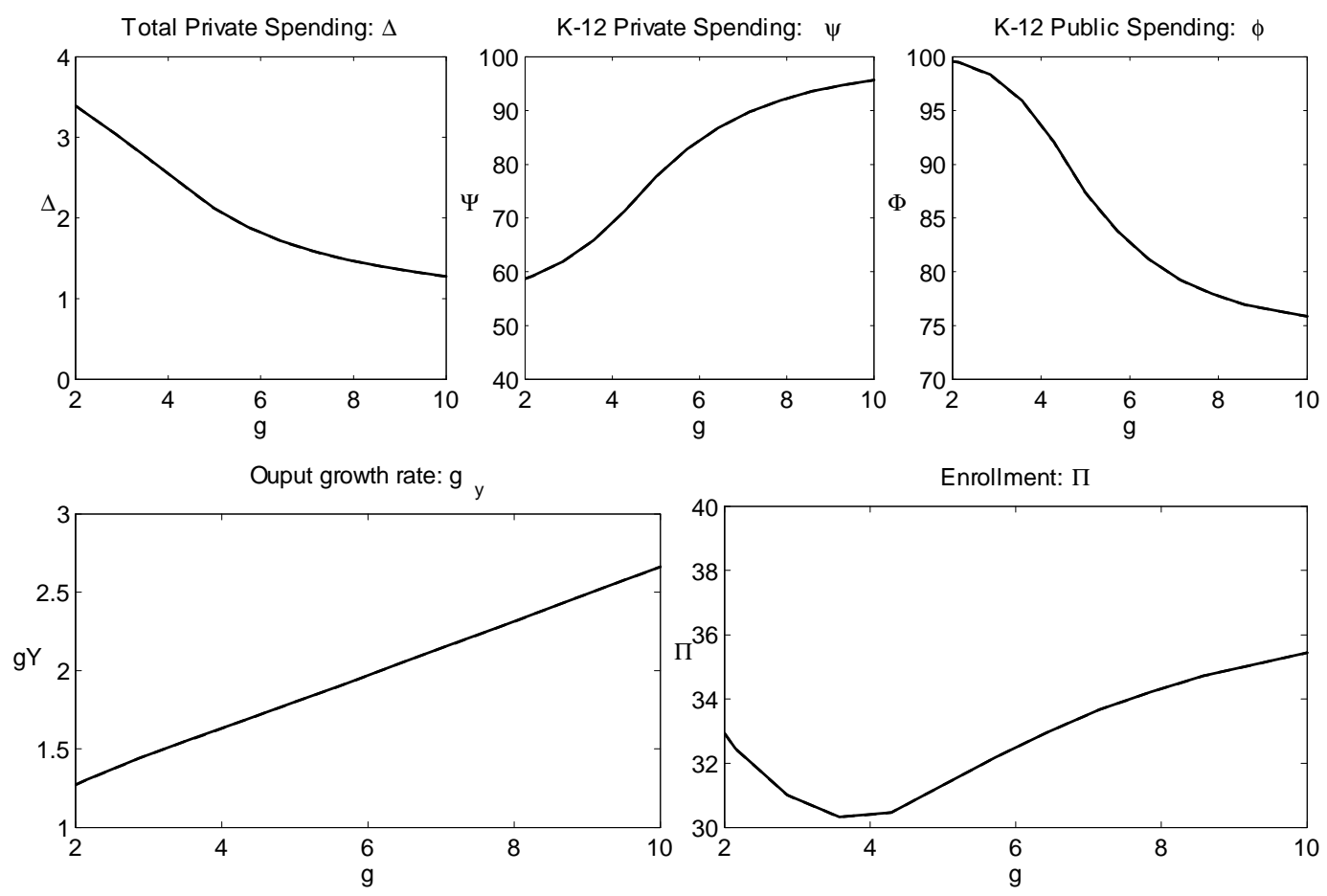

Figure 2: Growth maximizing structure of the public spending.

of the education public budget, it is optimal to allocate a higher share of funds to the first educational stage where resources have a higher marginal productivity. This result is in line with the results in Blankenau (2005) who finds in a different model that government finances tertiary education only when the total public spending on education $(g)$ exceeds a certain threshold and then, its share increases with the size of the budget. However, given that public education budgets are generally lower than $10 \%$ of GDP, the growth maximizing K-12 fraction declines slowly and stays above $70 \%$. This is consistent with the shares observed in the data that range from $58 \%$ to $77 \%$. The intuition for the high-share of public spending allocated to K-12 relies on the crowding out effect that an increase in $g$ has on private education contributions. At lower levels of $\Delta$, households rebalance their allocation of educational inputs towards primary education (higher $\psi$ ). In turn, this makes public resources more productive in the first stage, hence the high level of $\phi$. This complementarity ultimately reduces the marginal productivity of public resources so that further increasing the budget size is accompanied by a lower share of K-12 spending.

Enrollment follows a non-monotonic pattern as public spending increases, similar to that described in the case of exogenous policies. First, the relative wage of the college educated grows faster than their relative human capital, due to the high 
elasticity of substitution in the production of final goods, causing a drop in enrollment rates. When $g$ exceeds a threshold (around 4\%) the increase in human capital dominates the decrease in skilled wages so the share of college educated starts going up. This is a general equilibrium effect, partially due to the simple structure of the model that, for example, does not account for skilled-biased technological progress or differences in abilities across agents.

Our analysis of growth-maximizing education policy suggests that (1) as countries invest more public resources in education, an increasing share should go toward advanced training. (2) Nonetheless, for total budgets under $10 \%$ of GDP, the K-12 stage should still receive the bulk of the public funds. Moreover, increased funding will generate a higher enrollment only after a critical size budget has been reached, despite the expanding support for higher education.

Our conclusions are broadly consistent with the observed composition of the educational public budgets in developed economies. However, there are important differences among the institutions and the organization of education across countries. The tax level is one of the main factors that has significant effects on the private incentives to invest in education, both in terms of amount invested and allocation across stages. In all the previous experiments, the tax rate was assumed to be fixed. We look at the effect of tax differences in the next section.

\section{$7 \quad$ Tax level effects}

Higher taxes diminish the disposable income and hence the overall resources directed to education. Moreover, higher tax levels do not necessarily imply higher public education spending as a fraction of total tax receipts. Average public education spending in the EU is somewhat lower than in the US despite a higher tax level. On the other side, Northern European countries have higher taxes than the European average but also higher public spending on education. We explore the predictions of this model regarding the optimal public policy at different tax levels, assuming education spending $g$ is independent of the tax level $\tau$.

In Figure 3 we compute the growth maximizing share of public K-12 spending for $\tau=\{0.25,0.4\}$. The two values reflect the general taxation level in US and EU, expressed as percentage of tax receipts in GDP. As one might expect, Figure 3 shows that higher taxes imply lower growth rates and lower overall private spending, at all levels of public spending $g$. It is however interesting to discuss the optimal K-12 shares in public and respectively private spending $(\phi$ and $\psi)$. The optimal fraction of public budget allocated to higher education $(1-\phi)$ is higher in economies with higher taxes. This happens because households' incentives to invest in education respond to the tax level in two ways. First, they decrease their total spending by way of an income effect. Second, they spend more on K-12 education, since, as we 

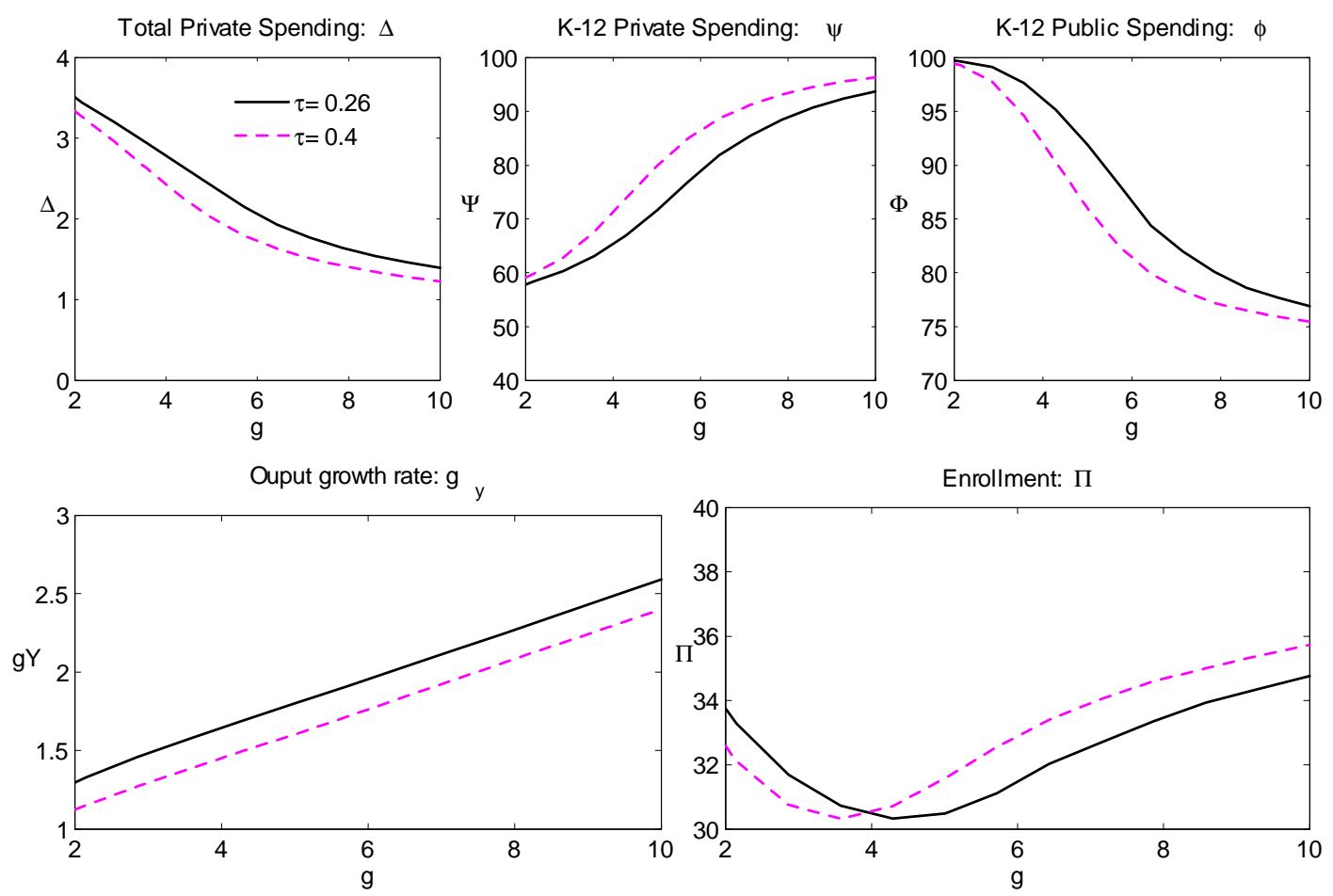

Figure 3: Growth maximizing structure of the public spending for different tax levels.

have shown in the previous sections, the returns to first stage spending are higher when $\Delta$ is low, which is the case here at all levels of $g$, due to the higher taxes.

The model's predictions for the private allocations fit well the data for OECD countries. EU countries spend less on education privately and tend to have a higher fraction of private resources spent on K-12 education compared to the United States or Canada. While households allocations seem to behave as suggested by our model, not the same thing can be said about public policy. Growth maximizing policies imply that high tax countries should focus more of their public budget on tertiary education to compensate for the withdrawal of private funds while the low tax countries should strengthen public support for primary and secondary education, as households have more incentives to invest in higher education.

However Table 1 shows that EU and US have allocated their education budgets in a very similar manner, despite the significant differences in taxation. United States even allocates a slightly higher share of public funds towards K-12.

In relative terms, this departure from the growth-maximizing policies indicated by the model, suggests that US could grow faster by increasing the public support to K-12 education and/or EU should improve its higher education to achieve higher 
growth. These implications mirror closely recent education policies, such as the No Child Left Behind Program in the US that aims at improving educational outcomes at early stages or the comprehensive Lisbon strategy in Europe that emphasizes investments in higher education and R\&D.

The bias toward higher education spending explains why a high tax country can achieve higher tertiary education attainment rates if the overall budget is sufficiently large. A good example in this respect are the Scandinavian countries.

They spend on average $7.3 \%$ of GDP on education while the average EU ${ }^{11}$ budget is $5.27 \%$. EU uses an average of $24.1 \%$ of the education budget to fund tertiary education. The same indicator is $32 \%$ for Finland, $31.4 \%$ for Norway, $29 \%$ for Sweden and $31 \%$ for Denmark. On the other side, average tertiary education attainment in these countries is $33.2 \%$, compared to the EU average of $22.9 \%$. Moreover, during the last decade, Scandinavian countries have outpaced the average annual growth in EU19 by $0.30 \%$. While this is due to a variety of reasons, among which steady deregulation and labor market reforms, high productivity growth is also linked to a well-educated work force that allowed these states to maintain a comparative advantage in knowledge intensive sectors, mainly information and communication technologies ${ }^{12}$.

Despite the size of the educated labor force, at equal education budgets, the high tax country has a lower growth rate since private spending is discouraged, which reduces the quality of education at both stages. However, larger education budgets produce higher growth. The latter factor seems to dominate the tax effect in the case of Scandinavian countries.

In our model, we exclude differences in ability hence individual reactions to taxation coming through reduced skill premium. This is why, for example, low tax countries, such as US and Canada have higher attainment rates than the OECD average. Lower skill premium is likely to diminish if not to offset the increased enrollment in the high tax country that is due mainly to increased public spending in tertiary education as a share in total budget. However, we capture a similar, albeit indirect, effect of taxation on education, through the parents' concern for the human capital of their children. This is an important link, in that it determines how the public policy will attempt to maximize growth, given the tax level.

\section{Conclusion}

Improving education quality figures high on political agendas everywhere. In particular, higher education competitiveness has been receiving a lot of attention during last decade. While more public funding is often touted as a panacea, the (dis)incentives for private investment should be given careful consideration. In this paper we study

\footnotetext{
${ }^{11}$ Here, EU refers to the 19 EU countries that are also OECD members.

${ }^{12}$ The EEAG Report on the European Economy 2007.
} 
the channels through which public spending triggers private responses in education funding.

The great diversity in how education is organized across countries, mainly with respect to the source of spending and the ownership of institutions, makes a general analysis difficult. We have tried to encompass the institutional variety by postulating very general production functions for human capital, in order to focus on the interaction between private and public education finance. We study this issue in a two-stage education framework where parents optimally choose the total resources to be spent on education and their allocation across stages. While the first stage is compulsory, young agents take the parental and the public inputs as given and decide whether to enroll in the second stage. The elasticity of substitution between private and public inputs at each stage is crucial for the analysis. While little is known on the degree of substitutability/complementarity between private and public inputs in K-12 versus tertiary education, our analysis shows that under very general conditions, the allocation of public inputs across education stages can be growth-improving if the households' response to policies is taken into account.

We derive the main results of the paper analytically for the particular case when private and public inputs are unit elastic substitutes in the first stage and perfect substitutes in the production of human capital in the second stage and study the effects of changing both the level of the education budget and its structure on households' education spending. Then, we generalize to the case where both stages display an elasticity of substitution higher than one.

First, we find that overall public spending crowds out private contributions in general, but increases the share of private spending on K-12 education. Conversely, assuming a fixed budget, a higher share of K-12 public funding generates higher private contributions at both stages and also an increase in private spending for tertiary education. As a result, the overall amount of resources used for education in the entire economy goes up. We also show that increasing enrollment in tertiary education may conflict with the objective of higher economic growth. Moreover, increasing the public budget for education has non-monotonic effects on enrollment.

Second, we look at growth-maximizing policies. Our results suggest that the optimal share of public spending devoted to K-12 decreases with the total public budget for education but remains high (over 70\%) irrespective of its size. We also find that countries with a high tax level will optimally direct a relatively higher fraction of public resources toward tertiary education while the households respond by focusing their spending on the first stage. If public education spending is high enough, higher taxes can generate higher enrollment if the country is pursuing growth maximizing policies. Our model is broadly consistent with observed private and public spending for OECD countries. Moreover, ranking data for US and EU against model predictions, we provide evidence that increasing public spending at the K-12 stage in 
the US and at the tertiary level in the EU are consistent with a growth-maximizing policy.

Education policies are very concerned with inequality and access to schooling. We do not explicitly address this issue here. An extended analysis using a heterogenous agent framework would allow for a more detailed description of the interaction between stages (by incorporating an admission threshold at the later stage) or type of public spending (means-tested aid, merit-based subsidies). Such a framework would also make possible a welfare comparison of the various funding schemes. Incorporating heterogeneity in ability would imply a more important role of the skill premium, which has important implications on the way public policy affects individuals' decisions and technological progress shapes education finance at all stages. We leave all these extensions for future research.

\section{References}

Aghion, P., Boustan, L., Hoxby, C. and Vandenbussche, J.: 2005, Exploiting States' Mistakes to Identify the Causal Impact of Higher Education on Growth, NBER Working Paper .

Barro, R. J.: 2001, Human Capital and Growth, American Economic Review 91(2), 12-17.

Bearse, P., Glomm, G. and Patterson, D. M.: 2005, Endogenous Public Expenditures on Education, Journal of Public Economic Theory 7(4), 561-577.

Blankenau, W.: 2005, Public schooling, college subsidies and growth, Journal of Economic Dynamics and Control (29), 487-507.

Blankenau, W., Cassou, S. and Ingram, B.: 2007, Allocating Government Education Expenditures Across K-12 and College Education, Economic Theory 31(1), 85112.

Brauninger, M. and Vidal, J. P.: 2000, Private versus public financing of education and endogenous growth, Journal of Population Economics 13(3), 387 - 401.

Cardak, B. A. and Givon, D.: 2004, Why the Poor Don't go to University: Attainment Constraints and Two-Staged Education, La Trobe University .

Carneiro, P. and Heckman, J. J.: 2003, Human Capital Policy, in B. M. Friedman (ed.), Inequality in America: What Role for Human Capital Policy?, MIT Press, Cambridge, MA. 
Cassou, S. P. and Lansing, K. J.: 2003, Tax Reform and Useful Public Expenditures, Manuscript .

Caucutt, E. M. and Kumar, K. B.: 2003, Higher education subsidies and heterogeneity: a dynamic analysis, Journal of Economic Dynamics and Control 27(8), 14591502 .

Clotfelter, C. T.: 1977, Public Services, Private Substitutes, and the Demand for Protection against Crime, American Economic Review 67(5), 867-77.

Cunha, F. and Heckman, J.: 2007, The Technology of Skill Formation, American Economic Review Papers and Proceedings 97(2), 31-47.

Driskill, R. A. and Horowitz, A. W.: 2002, Investment in Hierarchical Human Capital, Review of Development Economics 6(1), 48-58.

Eckstein, Z. and Zilcha, I.: 1994, The effects of compulsory schooling on growth, income distribution and welfare, Journal of Public Economics (55), 339-359.

Glomm, G. and Kaganovich, M.: 2003, Distributional Effects of Public Education in an Economy with Public Pensions, International Economic Review 44(3), 8031204.

Glomm, G. and Ravikumar, B.: 1992, Public versus private investment in human capital: endogenous growth and income inequality, Journal of Political Economy (4), 818-834.

Glomm, G. and Ravikumar, B.: 1998, Flat-rate taxes, government spending on education and growth, Review of Economic Dynamics (1), 306-325.

Hanushek, E. A. and Kimko, D. D.: 2000, Schooling, Labor-Force Quality, and the Growth of Nations, American Economic Review 90(5), 1184-1208.

Heckman, J. J. and Masterov, D. V.: 2007, The Productivity Argument for Investing in Young Children, Technical report, National Bureau of Economic Research, Inc.

Heckman, J. J., R, L. and J, S.: 1999, The Economics and Econometrics of Active Labor Market Programs, in O. A. Card and David (eds), Handbook of Labor Economics, Vol. 3A, Elsevier, Amsterdam.

Houtenville, A. and Conway, K. S.: 2001, Parental effect, school resources, and student achievement, Manuscript, Cornell University .

Jacobs, B. and van der Ploeg, F.: 2005, Guide to Reform of Higher Education: A European Perspective. 
Jamison, E. A., Jamison, D. T. and Hanushek, E. A.: 2006, The Effects of Education Quality on Income Growth and Mortality Decline, National Bureau of Economic Research Working Paper Series No. 12652.

Kaganovich, M.: 2005, Education Reform and Access to Public Education in Russia, Indiana University, mimeo .

Kaganovich, M. and Zilcha, I.: 1999, Education, social security and growth, Journal of Public Economics (71), 289-309.

Kim, H.-K.: 2001, Is there a crowding-out effect between school expenditure and mother's child care time? , Economics of Education Review 20, 71-80.

Krueger, A. B. and Lindahl, M.: 2001, Education for growth: why and for whom?, Journal of Economic Literature (39), 1101-1136.

Krusell, P., Ohanian, L. E., Rios-Rull, J.-V. and Violante, G. L.: 2000, CapitalSkill Complementarity and Inequality: A Macroeconomic Analysis, Econometrica 68(5), 1029-1054.

LaLonde, R. J.: 1995, The Promise of Public Sector-Sponsored Training Programs, Journal of Economic Perspectives 9(2), 149-68.

Li, W.: 2005, Private Expenditures, Family Contributions, and Financial Aid in Chinese Higher Education, Economics of Education Institute, Beijing University .

Lucas, R. E. J.: 1990, Supply-Side Economics: An Analytical Review, Oxford Economic Papers 42(2), 293-316.

Nordblom, K.: 2003, Is increased public schooling really a policy for equality? The role of within-the-family education , Journal of Public Economics 87(9-10), 19431965.

OECD: 2006, Education at a Glance. OECD INDICATORS, Technical report.

Psacharopoulos, G. and Patrinos, H. A.: 2004, Returns to Investment in Education: A Further Update, Education Economics 12(2).

Restuccia, D. and Urrutia, C.: 2004, Intergenerational Persistence of Earnings: The Role of Early and College Education, American Economic Review 94(5), 13541378.

Romer, P. M.: 2000, Should the Government Subsidize Supply or Demand in the Market for Scientists and Engineers?, NBER Working Paper No. 7723. 
Sapir, A., Aghion, P. and Bertola, G.: 2003, An agenda for a growing Europe. Making the E.U. Economic System Deliver , Report of an Independent High-Level Study Group established on the initiative of the President of the European Commission .

Stokey, N. L. and Rebelo, S.: 1995, Growth Effects of Flat-Rate Taxes, Journal of Political Economy 103(3), 519-50.

$\mathrm{Su}, \mathrm{X}$ : : 2004, The allocation of public funds in a hierarchical educational system, Journal of Economic Dynamics and Control (28), 2485-2510. 


\section{Appendix A}

Proof of Proposition 1. Consider a restricted optimization problem in which the parent can only choose the allocation of resources across K-12 and tertiary education, $\left(\psi_{t}\right)$, taking as given the total share of resources devoted to education $\left(\Delta_{t}\right)$. Substituting (2) and (3) in (10), the parent's problem can be written as follows:

$$
\begin{aligned}
\max _{\psi_{t}} U= & \ln \left[Y_{t}(1-\tau)\left(1-\Delta_{t}\right)\right]+\mu \rho[1-\Pi(1-\theta)] \ln (\phi g)+\mu(1-\rho)[1-\Pi(1-\theta)] \times \\
& \ln \left[\psi_{t} \Delta_{t}(1-\tau)\right]+\mu \Pi(1-\theta) \ln \left[(1-\phi) g+\Delta_{t}\left(1-\psi_{t}\right)(1-\tau)\right]+\mu \ln Y_{t}
\end{aligned}
$$

Denote the first order condition $f\left(\psi_{t}\right)$ :

$$
\begin{aligned}
f\left(\psi_{t}\right) & =\mu(1-\rho)[1-\Pi(1-\theta)] \frac{1}{\psi_{t}}-\mu \Pi(1-\theta) \frac{\Delta_{t}(1-\tau)}{(1-\phi) g+\Delta_{t}\left(1-\psi_{t}\right)(1-\tau)} \gtreqless 0 \text { with CS, } \\
& <0 \text { if } \psi_{t}=0, \quad>0 \text { if } \psi_{t}=1
\end{aligned}
$$

Since $f\left(\psi_{t}\right)$ is a decreasing function of $\psi_{t}, f\left(\psi_{t}\right)=0$ has at most one solution. The solution is in the interval $(0,1)$ if the following two conditions are satisfied:

$$
\begin{aligned}
& \lim _{\psi_{t} \rightarrow 0} f\left(\psi_{t}\right)>0 \\
& \lim _{\psi_{t} \rightarrow 1} f\left(\psi_{t}\right)<0
\end{aligned}
$$

We can see that the first condition holds since $\lim _{\psi_{t} \rightarrow 0} f\left(\psi_{t}\right)=\infty$. The second condition holds iff:

$$
\mu(1-\rho)[1-\Pi(1-\theta)]-\mu \Pi(1-\theta) \frac{\Delta_{t}(1-\tau)}{(1-\phi) g}<0
$$

Consequently, there exists a threshold $\widetilde{\Delta}=\frac{(1-\rho)[1-\Pi(1-\theta)](1-\phi) g}{\Pi(1-\theta)(1-\tau)}$ such that $\psi_{t} \in(0,1)$ if $\Delta>\widetilde{\Delta}$ and $\psi=1$ otherwise. If $\psi_{t}$ is interior, it is the solution of $f\left(\psi_{t}\right)=0$. Using 33 we get:

$$
\psi_{t}=\frac{(1-\rho)[1-\Pi(1-\theta)]}{1-\rho[1-\Pi(1-\theta)]}\left\{\frac{(1-\phi) g}{\Delta_{t}(1-\tau)}+1\right\}
$$

Thus the proposition establishes that for each $\Delta_{t}<\widetilde{\Delta}$, there exists a unique $\psi_{t}=\psi\left(\Delta_{t}\right) \in(0,1)$, defined by $(37)$. 
Proof of Proposition 2. In this proposition we solve the parent's problem in a sequential fashion. First we consider another restricted problem in which the parent can only choose the total share of resources devoted to education $\left(\Delta_{t}\right)$ taking as given the allocation across stages $\left(\psi_{t}\right)$ and find $\Delta_{t}=\Delta\left(\psi_{t}\right)$. Then, in the second step, we use $\psi_{t}=\psi\left(\Delta_{t}\right)$ from Proposition 2 to solve for the equilibrium $\psi_{t}$ and $\Delta_{t}$.

Step 1. Substituting (2) and (3) in (10), the parent's problem can be written as follows:

$$
\begin{aligned}
\max _{\Delta_{t}} U= & \ln \left[Y_{t}(1-\tau)\left(1-\Delta_{t}\right)\right]+\mu \rho[1-\Pi(1-\theta)] \ln (\phi g)+\mu(1-\rho)[1-\Pi(1-\theta)] \times \\
& \ln \left[\psi_{t} \Delta_{t}(1-\tau)\right]+\mu \Pi(1-\theta) \ln \left[(1-\phi) g+\Delta_{t}\left(1-\psi_{t}\right)(1-\tau)\right]+\mu \ln Y_{t}
\end{aligned}
$$

It can be easily checked that

$$
\begin{aligned}
& \lim _{\Delta_{t} \rightarrow 0} \frac{\partial U\left(\Delta_{t}\right)}{\partial \Delta_{t}}=-\infty \\
& \lim _{\Delta_{t} \rightarrow 1} \frac{\partial U\left(\Delta_{t}\right)}{\partial \Delta_{t}}=+\infty
\end{aligned}
$$

Moreover, the function $\frac{\partial U\left(\Delta_{t}\right)}{\partial \Delta_{t}}$ is decreasing in $\Delta_{t}$. Together with 38 and 39 this implies the parent's restricted problem has a unique solution in the interval $(0,1)$. Thus, the household's problem yields a unique and interior solution $\Delta_{t} \in(0,1)$ for all $\psi_{t} \in[0,1]$.

Step 2. We consider two subcases:

a) Suppose $\Delta_{t}>\widetilde{\Delta}$. The first order condition with respect to $\Delta_{t}$ is:

$$
-\frac{1}{1-\Delta_{t}}+\frac{\mu(1-\rho)[1-\Pi(1-\theta)]}{\Delta_{t}}+\frac{\mu \Pi(1-\theta)\left(1-\psi_{t}\right)(1-\tau)}{(1-\phi) g+\Delta_{t}\left(1-\psi_{t}\right)(1-\tau)}=0
$$

Using (37) in 40) and rearranging we obtain the following solutions for $\Delta_{t}$ and $\psi_{t}$ :

$$
\begin{aligned}
& \Delta_{t}=\Delta=\frac{\mu(1-\tau)\{1-\rho[1-\Pi(1-\theta)]\}-g(1-\phi)}{(1-\tau)\{1+\mu\{1-\rho[1-\Pi(1-\theta)]\}\}} \text { and } \\
& \psi_{t}=\psi=\frac{\mu(1-\rho)[1-\Pi(1-\theta)][1-\tau+g(1-\phi)]}{\mu(1-\tau)\{1-\rho[1-\Pi(1-\theta)]\}-g(1-\phi)}
\end{aligned}
$$

The solution for $\Delta$ obtained above needs to satisfy $\Delta>\widetilde{\Delta}$. This is the case when:

$$
\frac{\mu(1-\tau)\{1-\rho[1-\Pi(1-\theta)]\}-g(1-\phi)}{\{1+\mu\{1-\rho[1-\Pi(1-\theta)]\}\}}>\frac{(1-\rho)[1-\Pi(1-\theta)](1-\phi) g}{\Pi(1-\theta)}
$$


Rearranging the expression above yields:

$$
\mu>\frac{g(1-\phi)}{\Pi(1-\theta)(1-\tau)-g(1-\phi)(1-\rho)[1-\Pi(1-\theta)]}
$$

b) Suppose $\Delta_{t}<\widetilde{\Delta}$. Using the fact that $\psi_{t}=1$ in 40 we get:

$$
\frac{\mu(1-\rho)[1-\Pi(1-\theta)]}{\Delta}=\frac{1}{1-\Delta}
$$

Rearranging, we obtain:

$$
\Delta=\frac{\mu(1-\rho)[1-\Pi(1-\theta)]}{1-\mu(1-\rho)[1-\Pi(1-\theta)]}
$$

Proof of Proposition 3. From 41 we can easily see that $\frac{\partial \Delta}{\partial g}<0$. From 42 we get:

$$
\frac{\partial \psi}{\partial g}=\frac{\mu(1-\rho)(1-\tau)[1-\Pi(1-\theta)](1-\phi)\{\mu\{1-\rho[1-\Pi(1-\theta)]\}+1\}}{\{\mu(1-\tau)\{1-\rho[1-\Pi(1-\theta)]\}-g(1-\phi)\}^{2}}>0
$$

Proof of Proposition 4. From 41 we can easily see that $\frac{\partial \Delta}{\partial \phi}>0$. Using 37 we get:

$$
\frac{\partial \psi}{\partial \phi}=-\frac{(1-\rho)[1-\Pi(1-\theta)]}{1-\rho[1-\Pi(1-\theta)]} \frac{g \Delta(1-\tau)+(1-\phi) g(1-\tau) \frac{\partial \Delta}{\partial \phi}}{[\Delta(1-\tau)]^{2}}<0
$$

Proof of Proposition 5. From (41) we obtain:

$$
\frac{\partial \Delta}{\partial \tau}=\frac{-\mu g(1-\phi)[1-\Pi(1-\theta)]}{\{(1-\tau)\{1+\mu\{1-\rho[1-\Pi(1-\theta)]\}\}\}^{2}}<0
$$

Using 42 yields:

$$
\frac{\partial \psi}{\partial \tau}=\frac{\mu g(1-\phi)(1-\rho)[1-\Pi(1-\theta)]\{1+\mu\{1-\rho[1-\Pi(1-\theta)]\}\}}{\{\mu(1-\tau)\{1-\rho[1-\Pi(1-\theta)]\}-g(1-\phi)\}^{2}}>0
$$




\section{Appendix B}

Calibration summary for the benchmark model

\begin{tabular}{|c|c|c|}
\hline \multicolumn{2}{|l|}{ Parameter } & Value \\
\hline Preferences & & \\
\hline Altruism & $\mu$ & 0.06 \\
\hline Human capital production - first stage & & \\
\hline Second stage duration & $n_{2}$ & 0.133 \\
\hline Input elasticity of substitution $\left(\frac{1}{1+\gamma_{1}}\right)$ & $\gamma_{1}$ & -0.4 \\
\hline $1^{\text {st }}$ stage share of private input & $\rho$ & 0.5 \\
\hline TFP - K-12 education & $B_{1}$ & 1 \\
\hline Human capital production - second stage & & \\
\hline Elasticity of K-12 ed. in production of tertiary ed. & $\theta$ & 0.2 \\
\hline Input elasticity of substitution $\left(\frac{1}{1+\gamma_{2}}\right)$ & $\gamma_{2}$ & -0.8 \\
\hline TFP - tertiary education & $B_{2}$ & 1.3 \\
\hline Output & & \\
\hline TFP & $A$ & 121 \\
\hline Elasticity of substitution $\left(\frac{1}{1+\eta}\right)$ & $\eta$ & -0.35 \\
\hline Unskilled labor share & $\gamma$ & 0.65 \\
\hline Government & & \\
\hline Income tax & $\tau$ & 0.36 \\
\hline Public spending for education (\%GDP) & $g$ & $5.54 \%$ \\
\hline Share of $g$ spent on K-12 & $\phi$ & $76 \%$ \\
\hline
\end{tabular}




\section{Sensitivity analysis}

\begin{tabular}{|c|c|c|c|c|c|}
\hline \multirow[t]{3}{*}{ Parameter } & & \multirow[t]{3}{*}{ Value } & \multicolumn{2}{|c|}{ Private spending } & \multirow{3}{*}{$\begin{array}{l}\text { Tertiary ed. } \\
\text { attainment } \\
\Pi\end{array}$} \\
\hline & & & Disp. inc. share & $\mathrm{K}-12$ share in $\Delta$ & \\
\hline & & & $\Delta$ & $\psi$ & \\
\hline \multirow{3}{*}{$\begin{array}{l}\text { Elasticity of substitution } \\
\text { between skilled and unskilled } \\
\text { labor }(1+\eta)^{-1}\end{array}$} & \multirow{3}{*}{$\eta$} & -0.3 & 1.832 & 85.055 & 34.709 \\
\hline & & -0.35 & 1.832 & 85.326 & 34.619 \\
\hline & & -0.4 & 1.832 & 85.634 & 34.509 \\
\hline \multirow{3}{*}{$\begin{array}{l}1^{\text {st }} \text { stage human capital } \\
\text { elasticity }\end{array}$} & \multirow{3}{*}{$\gamma_{1}$} & -0.3 & 2.000 & 87.033 & 34.425 \\
\hline & & -0.4 & 1.832 & 85.326 & 34.619 \\
\hline & & -0.5 & 1.636 & 82.926 & 34.844 \\
\hline \multirow{3}{*}{$\begin{array}{l}2^{\text {nd }} \text { stage human capital } \\
\text { elasticity }\end{array}$} & \multirow{3}{*}{$\gamma_{2}$} & -0.9 & 1.690 & 96.054 & 33.173 \\
\hline & & -0.8 & 1.832 & 85.326 & 34.619 \\
\hline & & -0.7 & 1.951 & 76.289 & 36.376 \\
\hline \multirow{3}{*}{$\begin{array}{l}1^{\text {st }} \text { stage weight } \\
\text { in the } 2^{\text {nd }} \text { stage }\end{array}$} & \multirow{3}{*}{$\theta$} & 0.1 & 1.855 & 75.711 & 36.510 \\
\hline & & 0.2 & 1.832 & 85.326 & 34.619 \\
\hline & & 0.3 & 1.844 & 91.950 & 33.149 \\
\hline \multirow{3}{*}{$\begin{array}{l}\text { Unskilled labor share } \\
\text { in output }\end{array}$} & \multirow{3}{*}{$\gamma$} & 0.6 & 1.854 & 76.060 & 41.827 \\
\hline & & 0.65 & 1.832 & 85.326 & 34.619 \\
\hline & & 0.7 & 1.845 & 92.140 & 27.987 \\
\hline
\end{tabular}

\section{Appendix C}

Here we analyze the role of complementarity of resources between stages by studying a more general human capital production function in the second stage, which is a CES in the amount of human capital accumulated in the second stage and the aggregate resources invested in the second stage:

$$
\begin{aligned}
h_{2 t} & =\left\{\theta h_{1 t}^{-\lambda}+(1-\theta)\left[\rho e_{1 t}^{-\gamma_{1}}+(1-\rho) b_{1 t}^{-\gamma_{1}}\right]^{-\frac{\lambda}{\gamma_{1}}}\right\}^{-\frac{1}{\lambda}} \\
\text { where } \lambda & \in[-1,+\infty), \gamma_{1} \in[-1,+\infty), 0<\theta<1,0<\rho<1 .
\end{aligned}
$$

This complementarity is captured by the importance attached to the amount of human capital accumulated in the first stage, which can be interpreted as a "preparation effect". Thus, $\lambda$ controls for the strength of this effect. For relatively low values of $\lambda$ the human capital acquired in the first stage can be easily replaced by adding extra-resources in the second stage (for example, remedial classes). As $\lambda$ increases, $\mathrm{K}-12$ human capital is more instrumental in producing tertiary education. While $\lambda$ is responsible for the substitution elasticity between first stage human capital and second stage spending, $\theta$ reflects the how much the early human capital contributes 
quantitatively to the college type human capital.

We vary the degree of complementarity between the level of preparation achieved and the amount of resources invested. The sensitivity analysis is shown in the table below.

\begin{tabular}{|c|c|c|c|c|}
\hline \multirow[t]{3}{*}{ Parameter } & \multirow[t]{3}{*}{ Value } & \multicolumn{2}{|c|}{ Private spending } & \multirow{3}{*}{$\begin{array}{l}\text { Tertiary ed. } \\
\text { attainment } \\
\Pi\end{array}$} \\
\hline & & Share in disp. inc. & $\mathrm{K}-12$ share in $\Delta$ & \\
\hline & & $\Delta$ & $\psi$ & \\
\hline elasticity between & -0.1 & 1.833 & 84.499 & 34.759 \\
\hline $1^{\text {st }}$ stage human capital & $\mathbf{0}$ & 1.832 & 85.326 & 34.619 \\
\hline and $2^{n d}$ stage spending & 0.1 & 1.832 & 86.140 & 34.480 \\
\hline
\end{tabular}

